\title{
Post-deposition annealing controlled structural and optical properties of RF magnetron sputtered $\mathrm{MoO}_{3}$ films
}

\section{S. Subbarayudu*, V. Madhavi, S. Uthanna}

Department of Physics, Sri Venkateswara University, Tirupati 517502, India

*Corresponding author. Tel: (+91) 9849700207; E-mail: srsuguru.phy@ gmail.com

Received: 17 November 2012, Revised: 06 January 2013 and Accepted: 12 January 2013

\section{ABSTRACT}

$\mathrm{MoO}_{3}$ films were deposited on Corning glass and silicon substrates held at room temperature (303 K) by RF magnetron sputtering of metallic molybdenum target at a fixed oxygen partial pressure of $4 \times 10^{-4}$ mbar and sputter pressure of $4 \times 10^{-2}$ mbar. The as deposited films were annealed in air at different temperatures in the range $473-673 \mathrm{~K}$. X-ray diffraction studies suggest that the as-deposited and the films annealed at $473 \mathrm{~K}$ were amorphous in nature, while those annealed at 573 and $673 \mathrm{~K}$ were polycrystalline with mixed phases of $\alpha$ - orthorhombic and $\beta$ - monoclinic $\mathrm{MoO}_{3}$. Scanning electron microscope images of the films annealed at 573 and $673 \mathrm{~K}$ exhibited nanoflower like and nanodisk like structures due to improvement in the crystallinity. Fourier transform infrared studies showed the characteristic vibrations of MoO3 with shift in the vibrational modes of $\mathrm{Mo}=\mathrm{O}$ and $\mathrm{Mo}-\mathrm{O}-$ Mo with increase of annealing temperature. The optical absorption edge of the films shifted towards lower wavelengths side with increase of annealing temperature. Optical band gap of as-deposited films was $2.98 \mathrm{eV}$ with refractive index 2.01, while those annealed at $673 \mathrm{~K}$ showed the optical band gap of $3.15 \mathrm{eV}$ and refractive index of 2.08 . The $\mathrm{MoO}_{3}$ films annealed at $673 \mathrm{~K}$ were of nanocrystalline with crystallite size of $39 \mathrm{~nm}$ with optical band gap of $3.15 \mathrm{eV}$ and refractive index of 2.08 were favorable for electron blocking and hole-selective layers in bulk-heterojuction solar cells. Copyright (C) 2013 VBRI press.

Keywords: RF sputtering; molybdenum oxide; post-annealing; structural; optical properties.

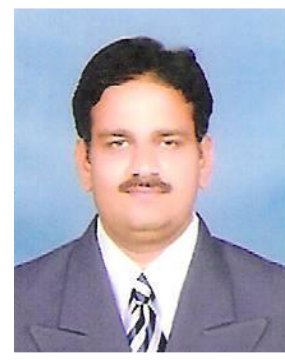

S. Subbarayudu is presently research scholar under the guidance of Prof. S. Uthana, Dept. Physics, Sri Venkateswara University, Tirupathi, India. Currently he is working on the RF magnetron sputtered $\mathrm{MoO}_{3}$ films. $\mathrm{He}$ received his Master Degree in Physics from the Sri Krishnadevaraya University, Anantapur, India during the year 1993-95.

\section{Introduction}

Molybdenum oxide $\left(\mathrm{MoO}_{3}\right)$ is a material finds potential applications due to its abundance and attractive properties such as catalyst, gas sensing and electrochromism [1-4]. $\mathrm{MoO}_{3}$ thin films exist in three phases namely: orthorhombic $\alpha$ - phase, monoclinic $\beta$ - phase and hexagonal phase. The crystal structure of $\beta-\mathrm{MoO}_{3}$ in which $\mathrm{MoO}^{6+}$ octahedral form a three dimensional network by sharing the corners with each other and well suited as a catalyst for number of chemical reactions. The amorphous $\mathrm{MoO}_{3}$ films formed by sol-gel dip coating exhibited electrochromic properties [5].
The lithium ions inserted into $\alpha-\mathrm{MoO}_{3}$ films lead to an increase in the charge storage capacity [6]. Orthorhombic $\alpha-\mathrm{MoO}_{3}$ nanoflakes were find applications in the cold cathode based electronics [7]. Recently, nanocrystalline oxide films attracted much for their promising applications in building of nanodevices and nanosensors [8-11]. Kocak et al. [12] realized the catalytic activity of electrodeposited $\mathrm{MoO}_{3}$ for nitrite oxidation. Allogho and Ashrit [13] reported on the photochromic activity of $\mathrm{MoO}_{3}$ films prepared by thermal evaporation to gauge the water content. Molybdenum oxide is a promising candidate for a back contact layer for cadmium telluride solar cells in superstrate configuration because of its high work function, possibly reducing the back contact barrier [14]. Various thin film deposition techniques such as thermal evaporation [15], pulsed laser deposition [16, 17], sputtering [5, 18-20], atomic layer deposition [21], electrodeposition [22, 23], spray pyrolysis [2], sol - gel process [6, 24, 25] and hot wire chemical vapour deposition [26] were employed for growth of $\mathrm{MoO}_{3}$ films. The phase, structure and surface morphology of the deposited films depend critically on the growth parameters and the adopted thin films deposition technique. The post-deposition annealing in air at different 
temperatures leads to the structural modification of the films [3, 5, 9]. Chang et al. [3] reported on the effect of air annealing at temperatures in the range $493-823 \mathrm{~K}$ in $\mathrm{RF}$ magnetron sputtered $\mathrm{MoO}_{3}$ films. The films annealed between 623 - $673 \mathrm{~K}$ were composed mixed phase of $\alpha$ and $\beta$ - phase $\mathrm{MoO}_{3}$, while $<623 \mathrm{~K}$ were single phase of $\beta$ $\mathrm{MoO}_{3}$ which is potential for ammonia sensing. Dhanasankar et al. [5] reported on the sol-gel coated $\mathrm{MoO}_{3}$ films that the optical band gap increased from 3.53 to 3.73 $\mathrm{eV}$ with increase of annealing in air at temperatures from 473 to $523 \mathrm{~K}$ and at higher temperatures of $723 \mathrm{~K}$ it decreased to $3.63 \mathrm{eV}$. Lin et al. [9] reported on the electron beam evaporated $\mathrm{MoO}_{3}$ films, and subsequently annealed in $\mathrm{N}_{2}$ and $\mathrm{O}_{2}$ for $10 \mathrm{~min}$ by rapid thermal annealing. The predominant $\beta-\mathrm{MoO}_{3}$ was achieved at annealing temperatures $<573 \mathrm{~K}$, where as $\alpha-\mathrm{MoO}_{3}$ realized at 673 $\mathrm{K}$. The optical band gap of the films decreased from 3.93 to $3.89 \mathrm{eV}$ with increase of annealing in $\mathrm{N}_{2}$ from 473 to 773 $\mathrm{K}$. The films annealed in $\mathrm{O}_{2}$ the band gap increased from 3.93 to $3.97 \mathrm{eV}$ with increase of annealing temperatures from 473 to $773 \mathrm{~K}$. From these studies, it revealed that the crystallographic structure and optical band gap of the $\mathrm{MoO}_{3}$ films critically depend on the annealing temperatures and ambient of annealing. Uthanna et al [19] reported on the DC magnetron sputtered $\mathrm{MoO}_{3}$ films formed at room temperature were of amorphous while those deposited at $473 \mathrm{~K}$ were orthorhombic phase. The optical band gap increased from 3.03 to $3.28 \mathrm{eV}$ and the refractive index increased from 2.03 to 2.08 with increasing substrate temperatures from 303 to $473 \mathrm{~K}$ due to improvement in the crystallinity of the films. In the present investigation, an attempt is made in the deposition of $\mathrm{MoO}_{3}$ films at room temperature by RF magnetron sputtering and studied the effect of post-deposition annealing in air on the structural and morphological and optical properties.

\section{Experimental}

\section{Preparation of $\mathrm{MoO}_{3}$ thin films}

$\mathrm{MoO}_{3}$ thin films were deposited onto glass and silicon substrates held at room temperature $(303 \mathrm{~K})$ by sputtering of pure metallic molybdenum target in oxygen and argon gas mixture using reactive RF magnetron sputtering technique. Metallic molybdenum target (99.99\% pure) with $50 \mathrm{~mm}$ diameter and $3 \mathrm{~mm}$ thickness was used for sputtering. The sputter chamber was evacuated by employing diffusion pump and rotary pump combination to achieve base pressure of $4 \times 10^{-6} \mathrm{~Pa}$. Pressure in the sputter chamber was measured with digital Pirani - Penning gauge combinations. Oxygen and argon of $99.99 \%$ purity were used as reactive and sputter gases for deposition of films. After achieving ultimate pressure, oxygen gas was introduced to the sputter chamber to a pressure of $4 \times 10^{-4}$ mbar. Later, argon gas was admitted to the sputter pressure of $4 \times 10^{-2}$ mbar. The required quantities of oxygen and argon gases were admitted into the sputter chamber through fine controlled needle valves followed by Aaloburg mass flow controllers (Model GFC 17). The $150 \mathrm{~W}$ power was supplied to the sputter target using RF power generator (Advance Energy Model ATX-600W). The sputter parameters fixed during the growth of the films are given in
Table 1. The as-deposited films were annealed in air for 2 hours at different temperatures in the range $473-673 \mathrm{~K}$.

\section{Characterization}

The as-deposited and the $\mathrm{MoO}_{3}$ films annealed at different temperatures were characterized by studying their chemical composition, crystallographic structure and surface morphology, chemical binding configuration and optical properties. The thickness of the deposited films was measured with a mechanical Veeco Dektak (Model 150) depth profilometer. A force of $10 \mu \mathrm{N}$ was applied over the sample surface with a swept length of $3 \mathrm{~mm}$ for $100 \mathrm{sec}$. The chemical composition of the films was analysed with energy dispersive X-ray Analysis (Oxford instruments Inca Penta FETx3) attached to a scanning electron microscope (Carl Zeiss, model EVO MA15). The crystallographic structure of the films was determined by using X-ray diffractometer (Bruker D8 Advance Diffractometer) with copper $\mathrm{K}_{\alpha}$ radiation wavelength of $\lambda=0.15406 \mathrm{~nm}$. The XRD profiles were taken for a $2 \theta$ range between $10^{\circ}$ and $60^{\circ}$ at the steps of $0.05^{\circ}$. The surface morphology of the films was analysed with scanning electron microscope (Hitachi SEM Model S-400). The chemical binding configuration of the films formed on silicon substrates was analyzed with Fourier transform infrared spectrophotometer (Nicolet Magana IR 750) was used to record the transmittance in the wavenumber range $300-1500 \mathrm{~cm}^{-1}$. The optical transmittance of the films formed on glass substrates was recorded using UV-Vis-NIR double beam spectrophotometer (Perkin - Elmer Spectrophotometer Lamda 950) in the wavelength range $300-1500 \mathrm{~nm}$.

Table 1. Sputter parameters fixed during the growth of the $\mathrm{MoO}_{3}$ films.

\begin{tabular}{ll}
\hline Sputter target & $:$ Molybdenum $(50 \mathrm{~mm} \times 3 \mathrm{~mm})$ \\
\hline Target to substrate distance & $: 65 \mathrm{~mm}$ \\
Ultimate pressure & $: 4 \times 10^{-6} \mathrm{mbar}$ \\
Oxygen partial pressure $\left(\mathrm{pO}_{2}\right)$ & $: 4 \times 10^{-4} \mathrm{mbar}$ \\
Sputtering pressure & $: 4 \times 10^{-2} \mathrm{mbar}$ \\
Sputter power & $: 150 \mathrm{~W}$ \\
Deposition time & $: 120 \mathrm{~min}$
\end{tabular}

\section{Results and discussion}

\section{Composition analysis}

The thickness of the deposited films was determined by using Veeco Dektak depth profilometer was in the range $910-980 \mathrm{~nm}$. The chemical composition of the $\mathrm{MoO}_{3}$ films was determined by using energy dispersive $\mathrm{X}$-ray analysis (EDAX). Fig. 1 shows the EDAX spectrum of the asdeposited $\mathrm{MoO}_{3}$ film. The spectrum contained characteristic constituents of molybdenum and oxygen in 
the film. The chemical composition of the films was determined from the peaks of molybdenum and oxygen. The atomic ratio of oxygen to molybdenum was 2.98: 1 . It indicated that the as-deposited films were nearly stoichiometric. It remains almost constant in the films annealed in air at different temperature.

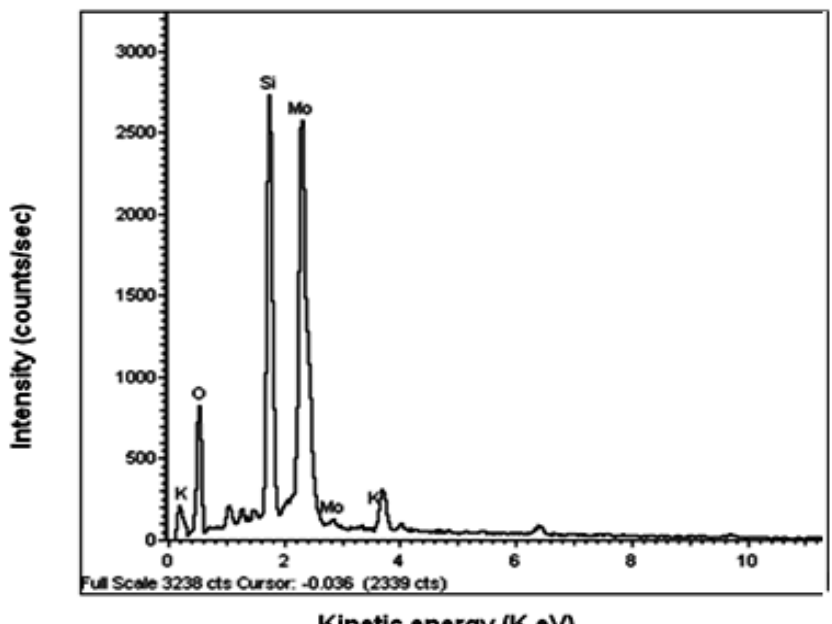

Fig. 1. EDAX spectrum of as deposited $\mathrm{MoO}_{3}$ film.

\section{XRD study}

Fig. 2 shows the XRD profiles of as-deposited and the $\mathrm{MoO}_{3}$ films annealed at different temperatures. The asdeposited $\mathrm{MoO}_{3}$ films showed no characteristic diffraction peaks which indicated that the grown films were amorphous in nature. The mobility of ad-atoms arriving on the substrate surface will be low in the as-deposited films and the interaction between the molybdenum and oxygen will be low hence of amorphous nature. The films annealed in air at $473 \mathrm{~K}$ were also amorphous (not shown in Fig. 2). It indicated that the thermal energy gained by annealing at $473 \mathrm{~K}$ was not sufficient to initiate crystallization of the amorphous phase $\mathrm{MoO}_{3}$ films. Post-deposition annealing of the films at $573 \mathrm{~K}$ exhibited the orientations (020), (040) and (060) related to the growth of orthorhombic $\alpha$-phase $\mathrm{MoO}_{3}$ [JCPDS card No. 76 - 1003]. The additional reflections of (011) and (201) were also present, which related to the growth of monoclinic $\beta$ - phase [JCPDS card No $86-1269$ ]. It revealed that the films annealed at $573 \mathrm{~K}$ were of mixed phase of orthorhombic $\alpha$-phase and monoclinic $\beta$ - phase $\mathrm{MoO}_{3}$. Further increase of annealing temperature to $673 \mathrm{~K}$, three additional (102), (110) and (400) reflections were also observed due to the formation of $\beta$ - phase $\mathrm{MoO}_{3}$ associated with $\alpha$ - phase $\mathrm{MoO}_{3}$. Thus, the as-deposited and the films annealed at $473 \mathrm{~K}$ were amorphous and the crystallinity of films increased with the increase of annealing temperatures $\geq 573 \mathrm{~K}$ and associated with the mixed phase of $\alpha$ - phase and $\beta$ - phase $\mathrm{MoO}_{3}$. The results achieved are in accordance with the reports of Chang et al. [3] where $\alpha$ - and $\beta$ - phase films were achieved by annealing of RF magnetron sputtered $\mathrm{MoO}_{3}$ films in the temperatures in the range $623-673 \mathrm{~K}$, and single phase $\alpha$ $\mathrm{MoO}_{3}$ films at $723 \mathrm{~K}$. Navas et al. [21] achieved monoclinic $\mathrm{Mo}_{8} \mathrm{O}_{23}$ and orthorhombic $\mathrm{MoO}_{3}$ phases by annealing of RF magnetron sputtered molybdenum oxide films annealed at 573 and $673 \mathrm{~K}$ respectively.

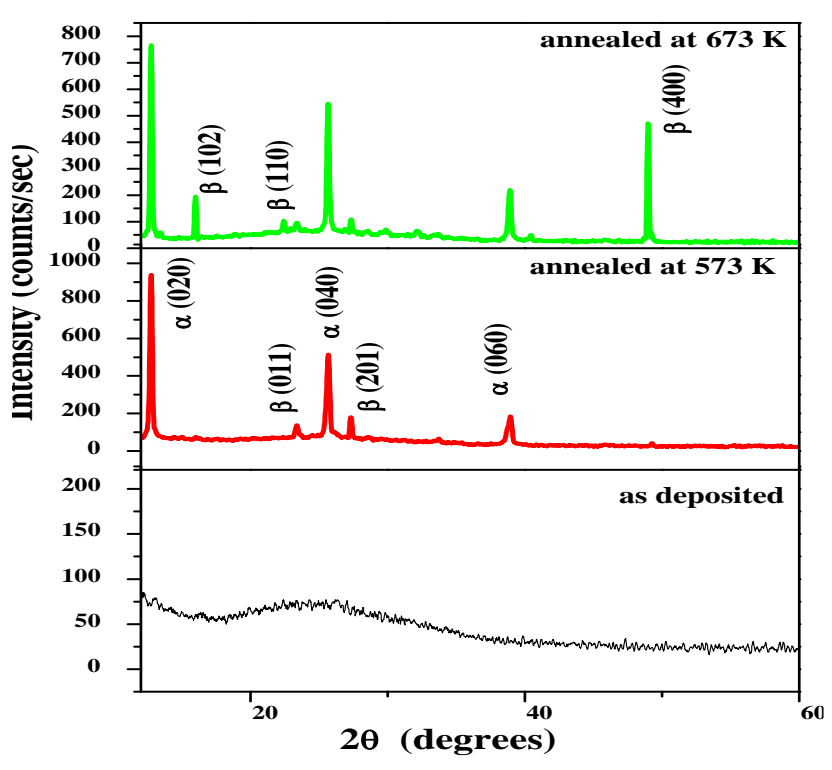

Fig. 2. XRD profiles of as-deposited and annealed $\mathrm{MoO}_{3}$ film.

Mahammad et al. [27] achieved amorphous films on unheated substrates by DC magnetron sputtering. The films formed at high oxygen partial pressure of $0.4 \mathrm{~Pa}$ and annealed at $823 \mathrm{~K}$ were completely transformed in to $\alpha$ phase $\mathrm{MoO}_{3}$ where as those formed at low oxygen partial pressure of $0.19 \mathrm{~Pa}$ showed weaker $\alpha$ - MoO3 peaks with a weak $\beta$ - MoO3 contribution after annealed at $873 \mathrm{~K}$. Fan et al. [28] reported that films deposited at substrate temperatures of 573 and $673 \mathrm{~K}$ by RF magnetron sputtering exhibited the growth of $\beta$ - phase $\mathrm{Mo}_{9} \mathrm{O}_{26}$ and $\alpha$-phase $\mathrm{MoO}_{3}$. Yang et al. [29] reported that $\beta$ - phase $\mathrm{MoO}_{3}$ films at substrate temperature of $473 \mathrm{~K}$ and $\alpha$ - phase at temperatures $\geq 573 \mathrm{~K}$ in electron beam evaporated films. Thus, the crystillinity increased with increase of annealing temperature which leads to the growth of nanocrystalline structure of $\mathrm{MoO}_{3}$. The crystallite size (L) of the films were calculated from the X-ray diffraction peaks by using Debye - Scherrer's relation [30].

Crystallite size, $L=0.89 \lambda / \beta \cos \theta$

where $\lambda$ is the wavelength of the $X$-ray $(0.15406 \mathrm{~nm}), \beta$ the full width at half maximum of diffraction intensity measured in radians and $\theta$ the diffraction angle. The crystallite size of the films increased from 32 and $39 \mathrm{~nm}$ with increase of annealing temperature from 573 and $673 \mathrm{~K}$ respectively. Thus, crystallite size increased with increase of annealing temperatures as noticed by decreasing in the width of FWHM. This confirms that the amorphous $\mathrm{MoO}_{3}$ films were modified into nanocrystalline with annealing temperature. The dislocation density $(\delta)$ and strain $(\varepsilon)$ developed in the films were calculated from the crystallite size using the relations [31],

Dislocation density, $\delta=1 / \mathrm{L}^{2}$

and, Strain, $\varepsilon=\beta \cos \theta / 4$ 
The dislocation density of the films decreased from the $7.6 \times 10^{14}$ to $6.3 \times 10^{14}$ line $/ \mathrm{m}^{2}$ with increase of annealing temperature from 573 to $673 \mathrm{~K}$ respectively. The strain developed in the films also decreased from $9.5 \times 10^{-4}$ to $8.7 \times 10^{-4}$ line $/ \mathrm{m}^{2}$ with increase of annealing temperature from 573 to $673 \mathrm{~K}$ respectively as shown in Table 2 . The thermal energy gained by annealing leads to rearrangement of atoms takes place and increase in the crystallite size. The increase of crystallite size leads to decrease in the grain boundary area which will decrease in the dislocation density. When the dislocation density decreased the strain in the films also decreased.

Table 2. FWHM, crystallite size, strain and dislocation density of $\mathrm{MoO}_{3}$ films.

\begin{tabular}{lcccc}
\hline Temperature & FWHM & Crystallite size \\
$($ Degree $)$ & $(\mathrm{nm})$ & $\begin{array}{c}\text { Strain } \\
\left(\text { Line }^{-2} \mathrm{~m}^{-1}\right)\end{array}$ & $\begin{array}{c}\text { Dislocation density } \\
\left(\mathrm{Line}^{2}\right)^{2}\end{array}$ \\
\hline & & & & \\
As-deposited & --- & --- & --- & --- \\
Annealed at $573 \mathrm{~K}$ & 0.218 & 32 & $9.5 \times 10^{-4}$ & $7.6 \times 10^{14}$ \\
Annealed at 673 K & 0.202 & 39 & $8.7 \times 10^{-4}$ & $6.3 \times 10^{14}$ \\
\hline
\end{tabular}

\section{Surface morphology}

Fig. 3 shows the scanning electron micrograph images of the as-deposited and the $\mathrm{MoO}_{3}$ films annealed at different temperatures. SEM of as-deposited films showed smooth surface morphology because of the amorphous phase. The films annealed at $573 \mathrm{~K}$ showed the nanoflowers like grain structure with the grain size of $3 \mu \mathrm{m}$. At higher annealing temperatures the molecules acquired the required thermal energy to promote the growth of films with larger size grains that is the growth of polycrystalline $\mathrm{MoO}_{3}$ films with mixed phase. Yang et al. [29] reported on the formation of platelet nanocrystallites uniformly distributed over the surface. In the present work, the films annealed at $673 \mathrm{~K}$ were of nanodisk like structure with grain size of about 800 $\mathrm{nm}$, due to the coalescence of neighboring crystallites driven by thermal energy by annealing. The change in surface morphology with different annealing temperatures was due to the modification of grain growth in to nanocrystalline with uniform size of crystallites. The morphological studies revealed that, the annealed films exhibited the layered structure at high annealing temperatures with enhancement in the crystallinity.

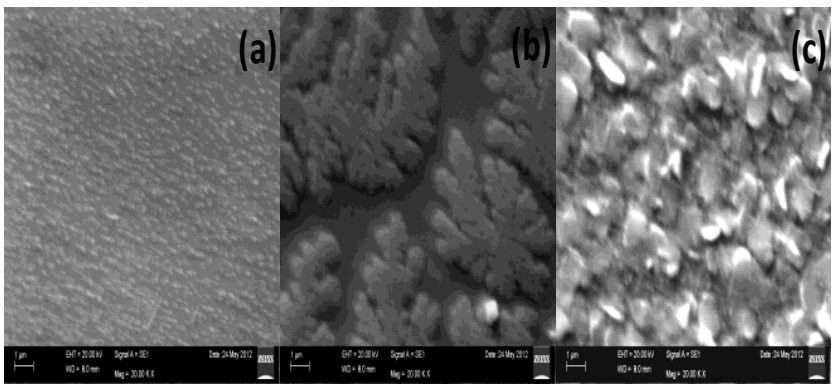

Fig. 3. SEM images of $\mathrm{MoO}_{3}$ films formed at a) $303 \mathrm{~K}$, and annealed at b) $573 \mathrm{~K}$ and c) $673 \mathrm{~K}$.
Fourier transforms infrared spectroscopy

Fourier transform infrared transmittance spectra of asdeposited and annealed $\mathrm{MoO}_{3}$ films formed on silicon substrates were recorded in the wavenumber range $300-$ $1500 \mathrm{~cm}^{-1}$ (Fig. 4). The FTIR spectra of as-deposited films contained broad band in between wavenumbers 600 and $1000 \mathrm{~cm}^{-1}$. There were three weak absorption bands at 795, 668 and $570 \mathrm{~cm}^{-1}$ which related to two stretching vibrational modes of $\mathrm{Mo}=\mathrm{O}, \mathrm{Mo}-\mathrm{O}$ and one transverse optical vibrations mode of Mo - O - Mo [21]. The FTIR spectra of the films annealed at $573 \mathrm{~K}$ showed the intense absorption bands at about 812, 672 and $573 \mathrm{~cm}^{-1}$. The absorption band observed at $812 \mathrm{~cm}^{-1}$ was attributed to the binding vibrations of $\mathrm{Mo}=\mathrm{O}$ in $\mathrm{Mo}^{6+}$ of the $\alpha$ - phase $\mathrm{MoO}_{3}[20]$. The films annealed at $673 \mathrm{~K}$ showed shift in the bands to 817,681 and $563 \mathrm{~cm}^{-1}$. The intensity of IR absorption bands was increased with increase of annealing temperature. This may be due to enhancement in the adatom mobility at high annealing temperatures, hence improved the crystallinity of the films. The intensity of the absorption band at $991 \mathrm{~cm}^{-1}$ was associated with the Mo = $\mathrm{O}$ stretching vibration and intensity enhanced with the increase of annealing temperature. Dhanasankar et al. [5] reported that weak absorption peak at $567 \mathrm{~cm}^{-1}$ which represents $\mathrm{Mo}-\mathrm{O}-\mathrm{Mo}$ band and the terminal $\mathrm{Mo}=\mathrm{O}$ double bands characterized by absorption bands appearing around $885-1007 \mathrm{~cm}^{-1}$. Ivanova et al. [32] also noticed, a strong band at $820 \mathrm{~cm}^{-1}$ and a weak absorption band at 545 $\mathrm{cm}^{-1}$, which represent the stretching vibrational modes of $\mathrm{Mo}=\mathrm{O}$, and transverse optical vibrations mode of Mo-OMo for orthorhombic $\mathrm{MoO}_{3}$ films annealed at $673 \mathrm{~K}$.
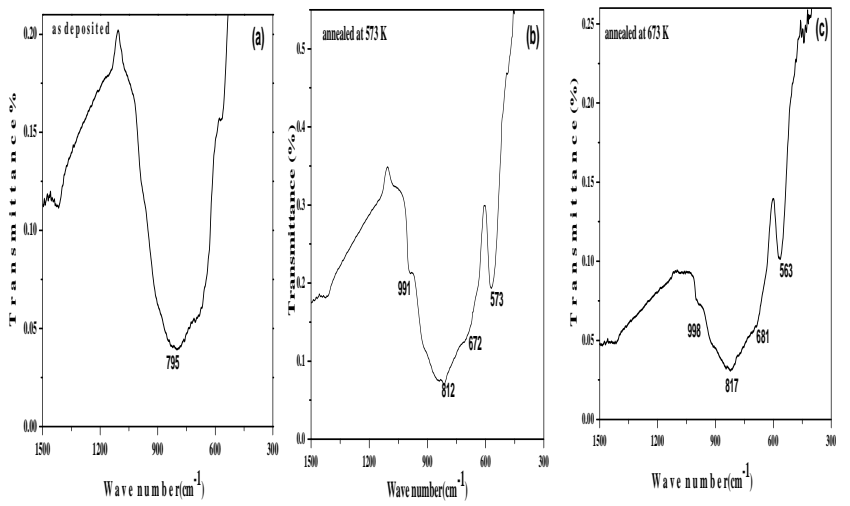

Fig. 4. FTIR spectra of $\mathrm{MoO}_{3}$ films: (a) as-deposited, and annealed at: (b) $573 \mathrm{~K}$ and (c) $673 \mathrm{~K}$

\section{Optical property}

Fig. 5 shows the optical transmittance spectra of asdeposited and annealed $\mathrm{MoO}_{3}$ films recorded in the wavelength range $300-1500 \mathrm{~nm}$. The as-deposited films showed an average transmittance of $60 \%$ (at wavelengths > $600 \mathrm{~nm}$ ). The films annealed at higher temperatures showed about $85 \%$ transmittance. The low transmittance in the asdeposited films was due to the presence of oxygen vacancies which can scatter the light photons hence the reduced transmittance. The increase of annealing temperature leads to reduction in the oxygen vacancies hence improved crystallinity, hence improved the transmittance. The optical absorption edge of the films 
shifted to lower wavelengths side with the increase of annealing temperature.

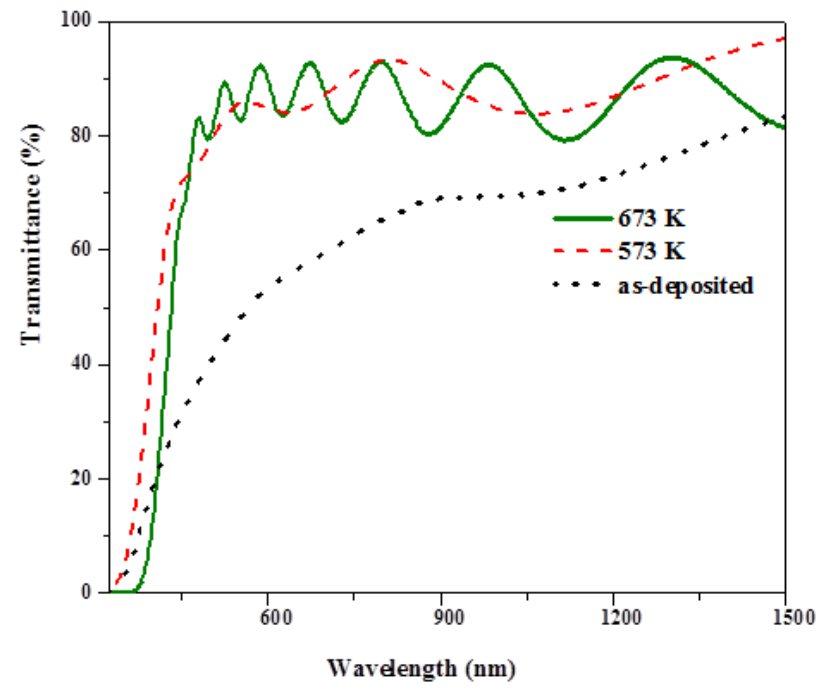

Fig. 5. Optical transmittance spectra of as-deposited and the $\mathrm{MoO} 3$ films annealed at different temperatures.

The optical absorption coefficient $(\alpha)$ of the films was evaluated from the optical transmittance $(\mathrm{T})$ data using the relation,

$$
\alpha=-(1 / t) \ln T
$$

where $t$ is the film thickness. The optical band gap of the films was calculated from the Tauc's [33] plots of $(\alpha h v)^{2}$ versus photon energy (hv) by assuming direct transition takes place in the films. The optical band gap of the asdeposited films was $2.98 \mathrm{eV}$. The band gap increased to 3.08 and $3.15 \mathrm{eV}$ in the films annealed at 573 and $673 \mathrm{~K}$ respectively. As the annealing temperature increased the optical band gap of the film increased. Sivakumar et al. [25] achieved low optical band gap of $2.8 \mathrm{eV}$ in the $\mathrm{MoO}_{3}$ films formed at room temperature, while those deposited at $473 \mathrm{~K}$ showed lower band gap of $2.3 \mathrm{eV}$. In the literature, Navas et al. [21] reported that the optical band gap values of $\mathrm{MoO}_{3}$ films were 3.77, 3.82 and $3.87 \mathrm{eV}$ for asdeposited and the films annealed at 573 and $673 \mathrm{~K}$ respectively. Increase in band gap with annealing temperature can be attributed to the partial filling of oxygen vacancies. The band gap values are in consistent with the value of 3.16 and $3.27 \mathrm{eV}$ obtained in electron beam evaporated films by Sain and reddy [15] for as-deposited and annealed $\mathrm{MoO}_{3}$ films respectively.

The refractive index (n) of the films was determined from the optical transmittance interference data employing Swanepoel's envelope method employing the relation [34],

$$
\begin{aligned}
& \mathrm{n}(\lambda)=\left[\mathrm{N}+\left(\mathrm{N}^{2}-\mathrm{n}_{0}^{2} \mathrm{n}_{1}^{2}\right)^{1 / 2}\right]^{1 / 2} \\
& \mathrm{~N}=2 \mathrm{n}_{0} \mathrm{n}_{1}\left[\left(\mathrm{~T}_{\mathrm{M}}-\mathrm{T}_{\mathrm{m}}\right) / \mathrm{T}_{\mathrm{M}} \mathrm{T}_{\mathrm{m}}\right]+\left[\left(\mathrm{n}_{0}^{2}+\mathrm{n}_{1}^{2}\right) / 2\right]
\end{aligned}
$$

where $T_{M}$ and $T_{m}$ are the optical transmittance maxima and minima and $\mathrm{n}_{0}$ and $\mathrm{n}_{1}$ the refractive indices of air and substrate respectively. The variation of refractive index with wavelength was shown in Fig. 6. The refractive index decreased with increase of annealing temperature. The refractive index (at wavelength of $600 \mathrm{~nm}$ ) of the asdeposited film was 2.01 and increased to 2.08 with increase of annealing temperature to $673 \mathrm{~K}$ due to improvement in the crystallinity and packing density of the films. In contrast to this, Mohamed and Venkataraj [27] observed that the refractive index decreased with increase of annealing temperature up to $723 \mathrm{~K}$, in the films formed at different sputter pressures, but after $773 \mathrm{~K}$ the refractive increased. Navas et al. [35] noticed that the refractive index of asdeposited films was 1.60 and decreased to 1.36 with the increase of annealing temperature to $673 \mathrm{~K}$.

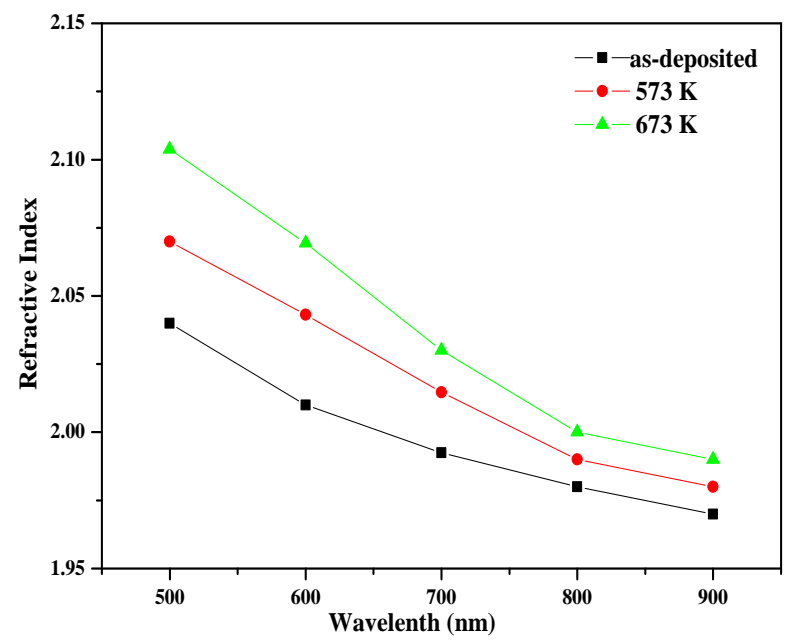

Fig. 6. Variation of refractive index with wavelength of as- deposited and annealed $\mathrm{MoO}_{3}$ film.

\section{Conclusion}

Thin $\mathrm{MoO}_{3}$ films were formed on Corning glass and silicon substrates held at room temperatures by sputtering of molybdenum target in an oxygen partial pressure of $4 \times 10^{-4}$ mbar. The as-deposited films were annealed in air for two hours at temperatures in the range $573-673 \mathrm{~K}$. X-ray diffraction studies revealed that the as-deposited films were amorphous in nature. Post-deposition annealing of films at $573 \mathrm{~K}$ was transformed into nanocrystalline with mixed phase of orthorhombic and monoclinic $\mathrm{MoO}_{3}$. Further increase of annealing temperature to $673 \mathrm{~K}$ the crystallinity of the films improved. The crystallite size of the films increased from 32 to $39 \mathrm{~nm}$ with the increase of annealing temperature from 573 to $673 \mathrm{~K}$ respectively. The Fourier transform infrared transmittance spectra of the films indicated that the presence of characteristic vibrational modes of $\mathrm{Mo}=\mathrm{O}$ and $\mathrm{Mo}-\mathrm{O}-$ Mo related to the growth of $\mathrm{MoO}_{3}$. Scanning electron micrographs of as-deposited films shows fine grain structure, nanoflower like structure growth in the films annealed at $573 \mathrm{~K}$ and nanodisk like structures at higher temperature of $673 \mathrm{~K}$. The optical transmittance of the as-deposited films was about $60 \%$ and it increased to $85 \%$ with increase of annealing temperature to $673 \mathrm{~K}$. The optical absorption edge of the films shifted towards lower wavelength side with increase of annealing temperatures. The optical band gap of the as-deposited films was $2.98 \mathrm{eV}$ and it increased to $3.15 \mathrm{eV}$ in the films annealed at $673 \mathrm{~K}$. The refractive index of the as-deposited 
film was 2.01 and increased to 2.08 with increase of annealing temperature to $673 \mathrm{~K}$ due to improvement in the crystallinity and packing density of the films.

\section{Reference}

1. Mizushima, T.; Fukushima, K.; Ohkita, H.; Kakuta, H. Appl. Catal A: 2007, 326, 106.

DOI: $\underline{10.1016 / \text { j.apcata.2007.04.006. }}$

2. Boudaoud, L.; Benramdana, N.; Desfeux, R.; Khalifa, B. Mathieu, C. Catal. Today 2006, 113, 230.

DOI: $10.1016 / \mathrm{j}$. cattod.2005.11.072.

3. Chang, W.C.; Qi , X.; Kuo, J.C.; Lee, S.C.; Ng, S.K,; Chen, D. Cryst. Eng. Commun. 2011, 13, 5125. DOI: $10.1039 / \mathrm{C} 1 \mathrm{CE} 05922 \mathrm{~J}$.

4. Lin, S.Y.; Wang, C.M.; Kao, K.S.; Chen, Y.C; Liu, C.C. J. Sol-gel. Sci. Technol. 2010, 53, 51.

DOI: $10.1007 / \mathrm{s} 10971-009-2055-6$.

5. Dhanasankar, M.; Purushothaman, K.K; Muralidharan, G. Appl. Surf. Sci. 2011, 257, 2074

DOI: $10.1016 /$ j.apsusc. 2010.09.052.

6. Brezesnski, T.; Wang, J.; Tolbert, S.H.; Dunn, B. Nat. Mater. 2010, $9,146$.

DOI: $10.1038 / \mathrm{nmat} 2612$

7. Yan, B.; Zheng, Z.; Zhang, J.; Gong, H., Shen, Z.; Huang, W.; Yu, T. J. Phys. Chem. C, 2009, 113, 20259.

DOI: $10.3139 / 146.110836$.

8. Wu, M.C.; Lee, C.S. Mater. Res. Bull. 2009, 44, 629.

DOI: $10.1016 / j$. materresbull.2008.06.034.

9. Lin, S.Y.; Chen, Y.C., Wang, C.M.; Hseich, P.T.; Shih, S.C. Appl. Surf. Sci. 2009, 255, 3868.

DOI: $10.1016 /$ j.apsusc. 2008.10 .069

10. Prakash, A.; Tripathi, A.; Pivin, J.C.; Tripathi, J.; Chawla, A.K.; Ramesh Chandra.; Kim, S.S.; Ashokan, K.; Avasthi, D.K. Adv. Mater. Lett. 2011, 2 (1), 7.

DOI: $10.5185 /$ Amlett.2010.12187.

11. Intelligent Nanomaterials, Wiley-Scrivener Pub. USA (2012). ISBN: 978.0.470.93879.9.John Wiley and Sons.

12. Kocak, S.; Ertas, F.N.; Dursun, Z. Appl. Surf. Sci. 2013, 265, 205. DOI: $10.1016 / \mathrm{J}$.apsusc. 2012.10.170.

13. Allogho, G.G.; Ashrit, P.V. Thin Solid Films 2012, 520, 2326 DOI: $\underline{10.1016 / J . t s f .2011 .09 .068 .}$

14. Gretener, C.; Perrenoud, J.; Kranz, L.; Baechler, C.; Yoon, S.; Romanyuk, Y.E.; Buecheler, S.; Tiwari, A.N. Thin Solid Films 2012. DOI: $10.1016 / j . t s f .2012 .11 .110$.

15. Sain, T.S.; Reddy, G.B. J. Appl. Phys. 2005, 98, 026104. DOI: $10.1063 / 1.1949271$.

16. Chen, J.S.; Cheah, Y.L.; Madhavi, S.; Lou, X.W. J. Phys. Chem. C $2010,114,8675$.

DOI: $10.1021 / \mathrm{jp} 1102109$

17. Ramana, C.V.; Julien, C.M. Chem. Phys. Lett. 2006, 428, 114. DOI: $10.1016 /$ j.cplett.2006.06.117.

18. Nirupama, V.; Gunasekhar, K.R.; Sreedhar, B.; Uthanna, S. Curr. Appl. Phys. 2010, 10, 272.

DOI: $10.1016 /$ j.cap.2009.06.005.

19. Uthanna, S.; Nirupama, V.; Pierson, J.F. Appl. Surf. Sci. 2010, 256, 3133.

DOI: $10.1016 / j$.apsusc. 2009.11.086.

20. Srinivasa Rao, K; Rajini Kanth, B.; Mukhopadhyay, P.K. Appl. Phys. A 2009, 9, 985.

DOI: $\underline{10.1007 / \mathrm{S} 00339.009 .5132 .3}$

21. Navas, I.; Vinod Kumar, R.; Lethy, K.J.; Detty, A.P.; Ganesan, V.; Sathe, V.; Mahadevan Pillai, V.P. J. Phys. D: Appl. Phys. 2009, 42, 175305 .

DOI: $10.1088 / 0022-3727 / 42 / 17 / 175305$.

22. Diskus, M.; Nilson, O.; Fjellveg, H. J. Mater. Chem. 2011, 21, 705. DOI: $10.1039 /$ COJM01099E

23. Patil, R.S.; Uplane, M.D.; Patil, P.S. Appl. Surf. Sci. 2006, 252, 8050.

DOI: $10.1016 / \mathrm{j}$.apsusc. 2005.10 .016 .

24. Martinez, H.M.; Torres, J.; Lopez Correno, L.D.; Rodriguez-Garcia, M.E. Mater. Character. 2013, 25, 184. DOI: $10.1016 /$ j.matchar.2012.11.002.

25. Sivakumar, R.; Gopalakrishnan, R.; Jayachandran, M.; Sanjeeviraja, C. Curr. Appl. Phys. 2007, 7, 51. DOI: $\underline{10.1016 / j . c a p .2005 .10 .001 .}$
26. Hsu, C.S.; Chan, C.C.; Huang, C.T.; Peng, C.H.; Hsu, W.C. Thin Solid Films 2008, 516, 4839.

DOI: $10.1016 / j . t s f .2007 .09 .019$.

27. Mohamed, S.H.; Venkatraj, S. Vacuum 2007, 81, 636. DOI: $10.1016 /$ j.vacuum. 2006.08 .006 .

28. Fan, X.; Fang, G.; Qin, P.; Sun, N.; Liu, N.; Zheng, Q.; Cheng, F.; Yuan, L.; Zhao, X. J. Phys. D: Appl. Phys. 2011, 44, 045101 DOI: $10.1088 / 0022-3727 / 44 / 4 / 045101$.

29. Yang, W.Q.; Wei, Z.R.; Zhu, X.H.; Yang, D.Y.; Phys. Lett. A, 2009, 373, 3965. DOI: $10.1016 /$ j. Physleta 2009.08.058.

30. Cullity, B.D. Elements of X-ray Diffraction, IInd Ed, Addison Wesley, London. 1978. DOI: $10.1107 /$ S0567739479000917.

31. Lalitha, S.; Sathyamurthy, R.; Senthilarasu, S.; Subbarayan, A.; Natarajan, K. Solar Energy Mater. Solar Cells. 2004, 82, 187. DOI: $10.1016 /$ j.solmat.2004.01.017.

32. Ivanova, T.; Gesheva, K.A.; Szekeres, A. J. Solid State Electrochem. 2002, 7, 21. DOI: $10.1007 / \mathrm{s} 10008$ 002-0274-7.

33. Tauc,J." Amorphous and Liquid Semiconductors", Plenum Press, New York 1974

34. Swanepoel, R.J. J. Phys. E: Sci. Instrum. 1983, 16, 1214. DOI: $10.1007 / \mathrm{s} 00339-010-5632-1$.

35. Navas, I; Vinod Kumar R ; Detty, A.P; Mahadevan Pillai, V.P Mater. Sci. Eng. 2009, 2, 012035.

DOI: $\underline{10.1088 / 1757-899 X / 2 / 1 / 012035}$.

\section{Advanced Materials Letters}

Publish your article in this journal

ADVANCED MATERIALS Letters is an international journal published quarterly. The journal is intended to provide top-quality peer-reviewed research papers in the fascinating field of materials science particularly in the area of structure, synthesis and processing, characterization, advanced-state properties, and applications of materials. All articles are indexed on various databases including DOAJ and are available for download for free. The manuscript management system is completely electronic and has fast and fair peer-review process. The journal includes review articles, research articles, notes, letter to editor and short
communications. 